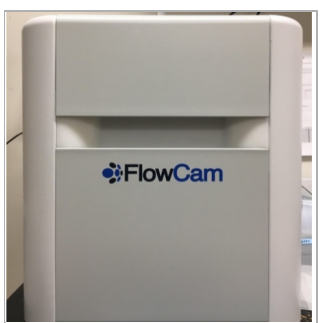

OCT 16, 2019

\section{open ひaccess}

DOI:

dx.doi.org/10.17504/protocol s.io.74qhqvw

\section{External link:}

http://wilhelmlab.utk.edu/

Protocol Citation: Brittany $\mathrm{N}$ Zepernick, Steven W Wilhelm 2019. Flow CAM 8000 Operation Protocol/Sample. protocols.io https://dx.doi.org/10.17504/p rotocols.io. 74 qhqvw

\section{MANUSCRIPT CITATION:}

Adapted from Fluid Imaging

Technologies, Inc. FlowCAM manual FlowCAM Manual Version 3.0 September 2011 FlowCAM 8000 Series User Guide

License: This is an open access protocol distributed under the terms of under the terms of
the Creative Commons the Creative Commons
Attribution License, which permits unrestricted use, distribution, and reproduction in any medium, provided the original author and source are credited

Protocol status: Working We use this protocol and it's working

Created: Oct 10, 2019

Last Modified: Oct 16, 2019

PROTOCOL integer ID: 28528

Keywords: Flow CAM, 8000 Operation, Flow protocol

\section{(3) Flow CAM 8000 Operation Protocol/Sample}

Brittany N Zepernick ${ }^{1}$, Steven W Wilhelm ${ }^{2}$

${ }^{1}$ University of Tennessee, Knoxville; ${ }^{2}$ The University of Tennessee, Knoxville

The Aquatic Microbial Ecology Research Group - AMERG (The Buchan, Zinser and Wilhelm labs)

Great Lakes Center for Fresh Wa

Brittany N Zepernick

University of Tennessee, Knoxville

\section{ABSTRACT}

The FlowCAM is a useful tool for morphological and physiological parameter analysis as well as identification of plankton. With over 30 different measurements available per cell, it facilitates cutting-edge analyses of environmental and cultural populations. To date, it has been generally employed for phytoplankton studies.

\section{GUIDELINES}

\section{Fluid Imaging Technologies Customer Support:}

+1-207-289-3200

customercare@fluidimaging.com

www.fluidimiaging.com/support

\section{Considerations:}

-The PPUI (particles per used image) should not be higher than 1.7-2.3 as this increases the risk of duplicate images being taken. However, diluting samples to a PPUI of 1.7-2.3 can result in low total cell/mL readings, and significantly increase the amount of time and volume needed per sample run. Should you elect to save time and volume, you can screen for duplicates by adding them to a library post-run, allowing you to run your samples at a higher PPUI to generate more data per second.

-If the flow cell becomes clogged, remove the flow cell and attempt to force $2 \%$ citrajet through the cell via a syringe.

-If this does not work, soak the flow cell in a tube with $2 \%$ citrajet for $1-2$ days and attempt to force air through flow cell using a syringe to ensure the flow cell is clear.

-If cells are very small (e.g., picocyanobacteria) then running the sample on autofocus instead of trigger may result in more cells being detected due to their size and potential low fluorescence. However, this is only ideal for cultures that are relatively homogenous or axenic and would result in a higher imaging rate of non-fluorescent particles in an environmental sample which would create more work as you fist through the images for debris.

Auto-Image Mode Size Settings: Image every particle (fluorescent or non-fluorescent)

$\begin{array}{llll}\text { Objective } & \text { Flow Cell }(\boldsymbol{\mu m}) & \text { Syringe }(\mathbf{m L}) & \text { Particle Size Range }(\boldsymbol{\mu m}) \\ 4 \mathrm{x} & 300 & 5.0 & 5-300 \text { (Zooplankton) } \\ 10 \mathrm{x} & 100 & 1.0 & 2-100 \text {. (Phytoplankton) } \\ 20 \mathrm{x} & 50 & 0.5 & 0.9-50 \text {. (Cyanobacteria) }\end{array}$

Laser-Trigger: Image fluorescent particles only (ideal for phytoplankton analysis)

$\begin{array}{llll}\text { Objective } & \text { Flow Cell }(\boldsymbol{\mu m}) & \text { Syringe }(\mathbf{m L}) & \text { Particle Size Range }(\mu \mathrm{m}) \\ 4 \mathrm{x} & 300 & 5.0 & 4-300 \text { (Zooplankton) } \\ 10 \mathrm{x} & 100 & 1.0 & 4-100 \text { (Phytoplankton) } \\ 20 \mathrm{x} & 50 & 0.5 & 3-50 \text { (Phytoplankton) }\end{array}$

\section{MATERIALS}

FlowCAM 8000

SAFETY WARNINGS

(1) See SDS (Safety Data Sheet) for hazards and safety warnings.

\title{
Power ON
}


Turn the fan ON using the switch on the back of the FlowCAM.

Press the circular power button on the top right. Power on the monitor.

* Always shut down FlowCAM when you have finished using it.

\section{Instrument Set-up}

2 You must consider the sample/community you are analyzing when selecting the objective, flowcell, and syringe. (Which I denote as the "size settings").

*For cyanobacterial analyses, use the $20 x$ objective with its designated flowcell and syringe.

Note

For analyzing larger phytoplankton such as diatoms, dinoflagellates, green algae etc, the 10x objective is more appropriate.

-You cannot mix and match objective sizes, flow cells, or syringes, as the analysis setting, flow rate, and calibration will be off.

(Reference Fluid Imaging Visual Spreadsheet Configuration Optimization Guide for additional inquiries and details, accessible online).

\section{Installing Objective}

3 Click Set-up and select Install Objective.

4 Carefully clean the lens of the objective with a lens wipe then screw it into the fitting on the objective stage (open black objective shroud, the black box directly to the left of flow cell). Click OK on the screen when complete.

5 Check the correct box on the screen for the objective magnification. Click OK.

\section{Installing Flow Cell}

6 No software prompt is needed to install the flow cell. The top of the flow cell is indicated with paint and also where the tiny etching is denoting its size and manufacturing details. 


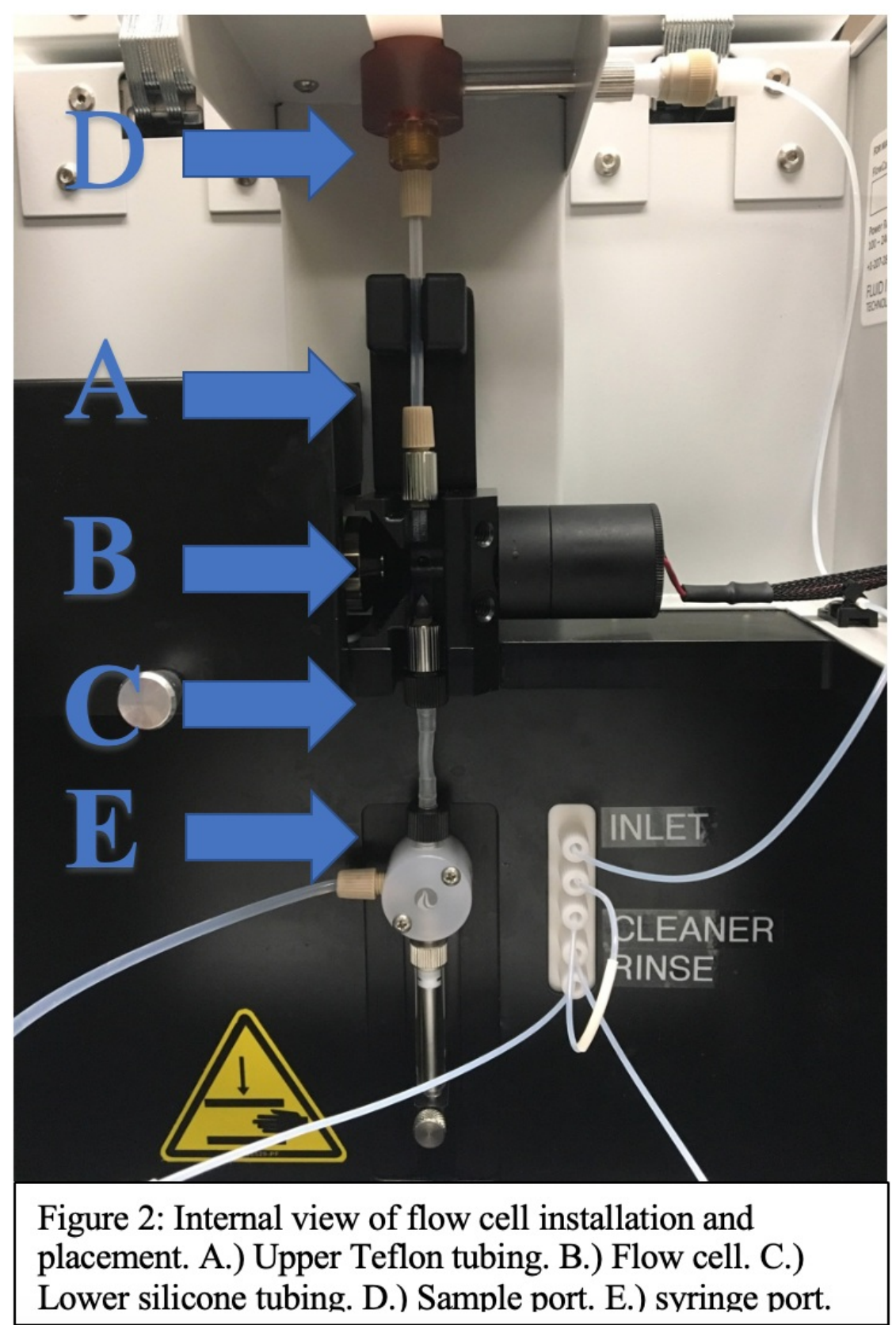

6.1 Screw the black tubing piece (lower silicone tubing denoted in Figure 2C, Step 6) into the bottom of the flow cell. Do not overtighten these as the torque can damage the flow cell.

6.2 Carefully fit the beige tubing piece into the top of the sample inlet port (Figure 2D) and tighten.

Carefully position the tubing into the fluid position sensor (black fitting under the sample port inlet) and position the flow cell into the flow cell retainer cavity underneath, ensuring it is not scratched. 
6.6 Take the tubing end of the lower silicone tubing (Figure 2E) and fit it over the syringe port. Ensure tubing is sitting straight and not twisted or scrunched.

\section{Installing Syringe}

7 Click Set-up and then select pump. Select change flow cell and turn the plunger lock screw counterclockwise three times. Press OK

8 The plunger will be pulled down by the syringe pump.

9 Turn the syringe counterclockwise and remove it. Press OK.

10 Screw in a new syringe and pull down the plunger so it is centered flush with the syringe pump. Press OK. The Syringe arm will push the plunger up into the syringe.

11 Tighten the plunger screw-lock on the syringe arm by turning clockwise and press OK. Select the size of the syringe installed and press OK.

12 Ensure the cleaner and rinse receptacles are full of 2\% citra-jet and Milli-Q respectively. Empty the waste receptacle.

\section{Cleaning and Priming}

13 Cleaning is recommended prior to every use and immediately after.

14 Open the FlowCam software (visual spreadsheet) and select set-up, pump, and make sure the correct syringe size is listed in the syringe size box.

15

\section{Click the "Clean/Rinse" button.}

Check the "Run at end of analysis" box under clean, unless you are optimizing a new sample, as the entire sample you enter will be purged at the end of the run when this box is checked. 
Should you be processing many samples back to back in a timely manner, you can choose to select "manually prime" and prime the machine with water and/or $2 \%$ citra-jet in between samples using the set-up feature and running the pump at $2.0 \mathrm{~mL} / \mathrm{min}$.

16 If you choose to let the machine perform the clean/rinse, check to make sure the "number of cycles to perform" says $2 \mathrm{~mL} / \mathrm{minute}$.

The "Pump Type" box should be selected for the "C80 Syringe".

17 Check to make sure the machine is being cleaned by ensuring the syringe is pumping liquid through the lines. There will be air bubbles and clicking sounds.

18

Once cleaning is finished, close the window.

Note

Occasionally machine prime will not fully fill the flow cell with the sample, causing bubbles and issues.

**If the FlowCam will not clean and rinse, take the syringe and fill with air, then disconnect the top first two lines located directly to the right of the flow cell. Attach the syringe to the second opening and push in air. Re-attach corresponding white connections and re-try cleaning and rinse.

\section{Autofocusing}

19 Select the "Setup/Focus" button at top of the screen. A live view of the camera will appear, along with a pump control box.

\section{Adjust Acceptable Region}

20 The red lines (acceptable region) indicate the area that will be imaged. Adjust the red lines to be just inside the edges of the flow cell. If the red lines are not centered, you will have to focus them.

Ways to adjust flow cell window:

20.1 Coarse adjustment: Turn the silver knob on the pi stage to center red lines inside the edges of the flow cell (not easily repeated but necessary if the window is off-center). If lines of flow cell are blurry/not well-defined this is okay.

20.2 Fine adjustment: Select "Set-Up" then click "Capture" and change the acceptable region (the red lines) by changing the left and right values and clicking "Apply".

21 Insert pipette tip and fill with milli-Q and bead solution (check table below to determine bead size and concentration, or FlowCAM Manual for more information accessible online).

Note

You will utilize the 15 or $100 \mathrm{~mm}$ beads depending on the objective used. For $20 \mathrm{x}$ and $10 \mathrm{x}$ settings use 3 drops of $15 \mathrm{~mm}$ beads. 
Autofocusing/Bead Calibration Sizes:

$\begin{array}{llll}\text { Objective } & \text { Nominal Size Beads }(\boldsymbol{\mu m}) & \text { \# drops beads } & \text { Volume } \mathrm{H}_{2} \mathrm{O} \text { Added }(\mathbf{m L}) \\ 4 \mathrm{x} & 100 & 5 & 1 \\ 10 \mathrm{x} & 15 & 3 & 1 \\ 20 \mathrm{x} & 15 & 3 & 1\end{array}$

Set flow rate in pump control box to $2.00 \mathrm{ml} / \mathrm{min}$ and click "Set".

\section{Autofocusing camera (calibration)}

24

Click "Auto-focus" and press "Next". Confirm the correct objective, flow cell, and syringe are installed, then press "Next".

25 Select "Best Focus Image". The machine will begin automatically focusing. A collage window will appear showing the imaged of the beads. If run fails, it is because the bead concentration was too low.

27 Aspirate the remaining lines by clicking "Okay" and remove the pipette tip. Once the machine is done aspirating, click "set-up" and "focus", "mode", go to the pump control, and pump 1-2 mL Milli-Q at $2 \mathrm{~mL} / \mathrm{min}$ to ensure the beads are clear of the flow cell and will not be imaged with your sample.

Take this time to ensure your red lines are in line, and adjust using the capture, acceptable region numerical input window.

The machine is now focused you can exit the window.

Autofocus camera once a week, or when you change objectives. Flush with water to ensure all the beads are cleared from the line when auto-focus is complete.

\section{Creating new context file or loading one}

29 Click "Context" and create a new or load a pre-existing file.

Note

The context is the optimized setting that allows the best imaging of your organism, it is composed of the following settings that you will have to optimize based on your organism. 
If this is an optimization sample, you can select "Stop when sample volume is aspirated or operator terminated analysis".

33 Fluorescent Measurement Settings: 3.74 minimum is optimal for most samples; max must remain at 6.84 .

Check "Noise Threshold Multiplier" and set "Gain" to $10^{3}$

Load pre-existing context file: Select "Load" and click "Load a Context File".

34 Capture: Distance to the nearest neighbor should read 0 for very concentrated samples, if they are branching or long specimen, then increase value to 1 and adjust accordingly.

Note

Close holes value should read 0 for colored samples and 1 or more for clear samples to ensure all the area of the cell is accounted for. Collage Image Border should read 2-5, set it to 2 . Variations in this setting will not affect your results.

35 -Select "Save Collage Image" "Save Binary Image" and Save Raw Camera Images" if you are setting up a context file for a new sample. -Otherwise, do not select the "Save Raw Camera Images" box.

-Check "Rolling Calibration" (ensures if a particle becomes stock on the surface of the flow cell during the run it will be calibrated into the background to avoid replicate analysis of the same particle.

-Select "Both Dark and Light Pixels" when analyzing phytoplankton, set both thresholds at 20 and adjust accordingly.

Flow Cell: Ensure the correct flow cell is selected

37 Fluidics: Enter sample volume to be analyzed and select flow rate based on the objective (see sheet from user guide titled FlowCam 8000 Series Visual Spreadsheet Configuration Optimization Guide").

-Ensure efficiency is within the correct range (approximately $70 \%$ ) and select manual prime with sample.

-Enable the dilution and ensure the ratio is set to 1 and enter sample volume and total volume.

Click "Find Ratio" or your values will not be saved. If sample is colored, it is likely too concentrated and must be diluted in milli-q or media (usually either 10fold or 100 -fold dilutions will be adequate).

38 Filter: Click ABD and select the minimum and maximum values based on your sample and the objective. Usually, set the minimum to the lowest value you expect and the maximum way above what you expect (ex. Minimum 2 and Maximum 10000).

-Based on the objective and the (FlowCam 8000 Series VisualSpreadsheet Configuration Optimization Guide") filter your sample using the corresponding filter.

Setting intensity: Click "Set-Up" and select "Camera Settings". Set the "Auto Background Intensity" to be 170 as this is recommended for phytoplankton.

\section{Running Sample}


41 Filtering sample: Select filter according to objective size to ensure the flow cell does not get clogged (10x objective use 100um filter. 20x objective use 50um filter).

41.1 Ensure you enter the dilution into the fluidics window of the context settings if you would like the machine to calculate the particle/mL accurately.

42.1 Perform dilution with milli-Q or media sample is suspended in.

42.2 Ensure you enter the dilution into the fluidics window of the context settings.

Note

*Dilution must be performed so the PPUI (particles per used image) is between 1-1.2, which is the optimal range for a sample run to prevent repeat imaging/data collection of the same particle as it passes through the flow cell. If the ppui reads higher than 2 , stop run and dilute sample (1:10 is a good starting dilution).

42.3 Once sample is loaded into pipette tip, click auto-image (any detectable object by the laser will be imaged) or trigger mode (only fluorescent particles will be imaged) to initiate acquisition of data.

42.4 Enter when you want to stop the run (time, cell number, volume, etc).

Note

*If this is a new sample and you are unsure of the optimal settings, run on "collect raw image" (found in the context settings) so you can alter the settings post-analysis.

42.5 This takes up a lot of storage, don't do this often and delete after optimal context file has been saved.

Note

*When analyzing the view all images, go to show and click "Binary Image Overlay" and "Particle Edge Trace". The binary image overlay should be fully shaded dark pink, if there are holes/unshaded regions, increase the "close holes" value in the context settings. The particle trace edge should capture the full perimeter of the cell in the bright green trace.

42.6 Auto-image: images every particle, fluorescent and non-fluorescent.

42.7 
42.9 Click "open view" to view all images. Can select a few irregular/unwanted images (such as bubbles, irregular particles, ect) and go to filter, select like images statistical) to screen entire run for like images. Delete images.

42.10 Save, run, and export data to excel sheet or can make a library.

\section{Cleaning and Removing Parts}

43 Once you have finished running your samples, got to set-up, pump controls, and select the clean and rinse setting and set for 2 cycles. Remove the pipette tip before starting 